Session 3148

\title{
Continuous Improvement of Engineering Technology Programs -- Coming Soon to a University Near You
}

\author{
Gregory Neff, Susan Scachitti, and Mohammad Zahraee \\ Purdue University Calumet, Hammond, Indiana
}

\begin{abstract}
While engineering technology programs have long had input from alumni, employers and industrial advisory committees, few departments have had a formal continuous improvement program in place. Continuous improvement has become a key component in the quality system of many businesses striving for a competitive edge. Research shows that no matter how solid an organization's foundation, if the organization does not continually improve, it will be surpassed by more ambitious competitors and begin to loose its customer base. Educational organizations are no exception. Realizing this, the Technology Accreditation Commission of the Accreditation Board for Engineering and Technology (TAC/ABET) has added continuous improvement into accreditation requirements for engineering technology programs. Program evaluation has been changing to increasingly emphasize the concept. The Engineering Accreditation Commission of the Accreditation Board for Engineering and Technology (EAC/ABET) was first to replace prescriptive accreditation requirements with outcome-based, assessment-driven objectives defined by the stakeholders in each program in its Engineering Criteria 2000 (EC 2000).
\end{abstract}

This paper will discuss what it means to establish a formal continuous improvement program and how the concept can be applied to engineering technology education. It will discuss various methods of assessment and continuous improvement efforts underway at Purdue University Calumet.

\section{Introduction}

TAC/ABET program evaluation has been changing to increasingly emphasize continuous improvement. Industrial advisory committees, employer and alumni surveys have long been required by TAC criteria. These provide assessment and continuous improvement feedback data for technology programs. A measure of the increasing importance of continuous improvement is evident by looking at the Engineering Technology Program Evaluation, form T4 questionnaire used by evaluation team members. For the 1992-93 accreditation cycle, the T4 had no questions 
on continuous improvement. For 1999-2000, there are five questions on the T4 form related to continuous improvement that program evaluators must answer.

A hint to faculty or administrators who are responsible for accreditation or reaccredidation is to download a copy of the T4 form from the TAC/ABET web site

http://www.abet.org/tac/tac\%5Fforms.html. If you can provide answers and supporting evidence for the questions posed in the T4, you have a tool as useful as a lighthouse beacon in cutting through any fog of misunderstanding surrounding requirements of the Criteria for Accrediting Programs in Engineering Technology. Use the T4 in preparing for the accreditation visit and you will be ready for the accreditation visitor who will be using the T4 to evaluate your program.

With the program evaluation cycle beginning in 1999, evaluators started looking for evidence that a written continuous improvement plan has been implemented and that assessment data are being used to improve the program. These requirements have been a part of the criteria for a number of years but evaluators did not check beyond survey data showing achievement. Beyond this year into the near future, the New Criteria for Accrediting Technology Programs beginning in the year 2001 (TC-2K) is performance based and heavily dependent on assessment and continuing improvement in its philosophy.

\section{Defining Continuous Improvement}

The term "continuous improvement" is derived from the essence of the Japanese term KAIZEN which is a systematic approach to the closing of gaps between customer expectations and the characteristics of process outputs. First used in the 1950's, it has since been known by terms such as Continuous Quality Improvement and Continuous Process Improvement as well as being closely tied, and almost synonymous, with the umbrella expression called Total Quality Management (TQM).

In an article in Quality Digest, Danny Langdon [1] states:

Continuous Process Improvement is designed to utilize the resources of the organization to achieve a quality-driven culture. Individuals must think, act, and speak quality. An organization attempts to reach a single-minded link between quality and work execution by educating its constituents to "continuously" analyze and improve their own work, the processes, and their work group.

Dale Besterfield [2] declares in his book that (among other things) we must continually improve by:

- Viewing all work as a process, whether it is associated with production or business activities.

- Making all our processes effective, efficient and adaptable.

- Maintaining constructive dissatisfaction with the present level of performance.

- Investigating activities that do not add value to the product or service, with the aim of eliminating those activities.

- Using benchmarking to improve competitive advantage.

- Innovating to achieve breakthroughs.

- Incorporating lessons learned into future activities. 
These basic concepts were initially used and developed in manufacturing environments and have since spread to use in the service industries such as health care, government and education. In service industries continuous improvement is often met with initial resistance based on the thought that the service industry can not duplicate or learn from the successful initiations of the manufacturing industries. This thought is far from the truth. In fact, most continuous improvement concepts are generic enough to apply to any organization, especially if the organization subscribes to the thought that "all work is a process," whether it is associated with a production or business activity.

In thinking of all work as a process, Besterfield has developed a process model to help visualize how continuous improvement is applied to any type of work (Figure 1). In this model the process itself is considered to be the interaction of some combination of people, materials, equipment, method, measurement, and the environment to produce an outcome such as a product, a service, or an input to another process. The process inputs and outputs are defined as any resource used or developed in the process such as money, material, information, data, products, services, etc. Outputs may also be inputs to another process. Also, outputs usually require performance measures and are designed to achieve certain desirable outcomes such as customer satisfaction. Finally feedback is provided in order to improve the process.

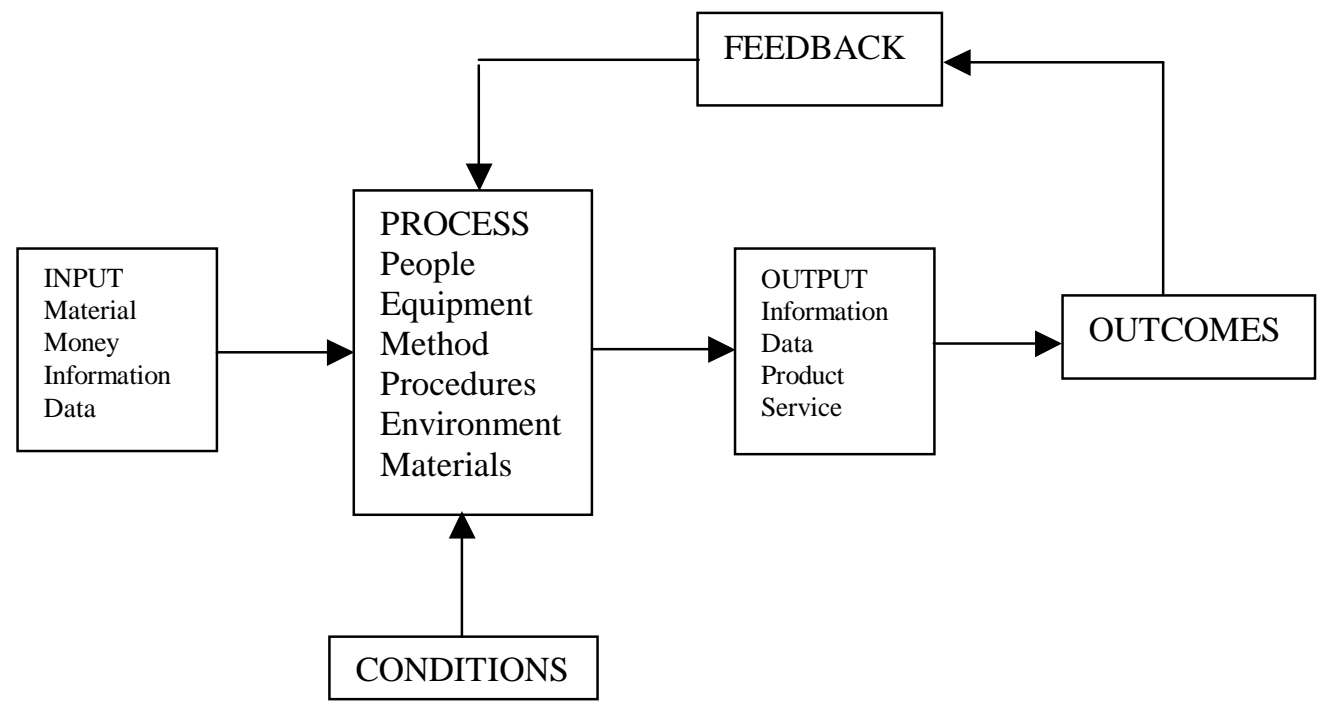

Figure 1 Continuous Improvement Process Model

We can use this model as a framework for continuous improvement in higher education. The process that will be addressed is the overall education process.

\section{Implementing Continuous Improvement in Higher Education}

When implementing a continuous improvement effort a logical place for organizations to begin is by creating a continuous improvement implementation team. This team is formed to organize, steer and prioritize all initiatives. One example of this in higher education, and specifically in an Engineering Technology program, was at Purdue University's (West Lafayette) MET

department. Their team was appointed in May 1994 and consisted of a chair and four members; 
one for curriculum, one for facilities, one for processes and one for student activities. It met monthly and acted as a catalyst to move the department's Continuous Quality Improvement (CQI) program into a proactive stance [3].

The concept of the continuous improvement implementation team being a catalyst is important in that one of the most important concepts of a successful program is total employee involvement. "Total" here means everyone. If a team functions as a creator and dictator of the program, the program will ultimately meet with resistance from other employees whose needs are not met or who do not understand the purpose of specific initiatives. Instead, the team must be the enabler for all employees to accomplish whatever is required to satisfy and ultimately delight their customers.

The focus on the customer is integral to the success of a continuous improvement program and therefore merits some discussion. It is only in identifying the customers of a process that the process itself can be assessed (and ultimately improved) so that it actually meets customer requirements. The understanding of customer requirements can then be translated into quantifiable goals and objectives that need to be met when performing a process.

In order to begin understanding a customer's requirements, the term customer must first be defined. A customer is defined as one who utilizes a product or service. Applying this definition to Besterfield's process model highlights that every process performed has an output (product or service) and therefore also has its own customers whether they are internal or external to the organization. The external customer is the customer that exists outside of the organization, but just as important to analyzing processes is the internal customer who exists within the organization and receives a product or service from another process within the organization.

In higher education the definition of customer is often simplified to encompass only the obvious external customers; the students and the employers who hire the students. These are not the only customers that need to be considered in order for continuous improvement to be implemented within a university. For example, on defining the process of scheduling course offerings, a university department must not only consider the requirements of possible student course conflicts (student as the customer) but also room conflicts (scheduling department as the customer) or faculty conflicts (faculty as the customer). When improving processes it is just as important to consider all of the internal customers as to consider all of the external customers of a process. Some other examples of university customers that may be overlooked are foundations, federal government agencies, other universities, accrediting agencies, alumni, citizens, local and state government.

After developing the processes to satisfy customer needs, an assessment of the outcome must be performed. This assessment should be a quantifiable form of feedback that can be compared to the goals and objectives that were developed to meet the customer needs. Through assessment, a university is able to monitor its achievements and identify areas for improvements. An action plan can then be developed to change any process that is in need of improvement.

Continuous improvement can be achieved by executing the tasks outlined below:

1) assessing a process 
2) identifying the customers of the process and the customer requirements

3) developing goals for the process

4) assessing the outcomes of the process

5) creating an action plan to adjust the process as needed.

\section{Continuous Improvement Plans for Purdue University Calumet METS Department}

The Manufacturing Engineering Technologies \& Supervision (METS) Department at Purdue University Calumet is implementing a formal continuous improvement program that addresses the all-inclusive "education process." Of course this process is made up of numerous individual processes encompassing a wide scope of customers and outputs. Due to the vastness of processes to assess, a prioritization and categorization of possible processes must be done. If TAC/ABET is identified as the customer requiring a formalized continuous improvement program, then the logical source of information to use is their criteria.

In order to satisfy the New Criteria for Accrediting Engineering Technology Programs (TC-2K) regarding continuous improvement, only one of the seven criteria areas must be addressed as a matter of priority; Assessment of the Program (criterion 6). It is identified because this criterion specifically requires continuous improvement as a component for evaluation by ABET evaluators. However, in the true spirit of the document, continuous improvement should also be applied toward all seven criteria: Students and Graduates (criterion 1), Program Characteristics (criterion 2), Faculty (criterion 3), Facilities (criterion 4), Institutional and External Support (criterion 5), and Individual Program Criteria (criterion 7). This initiative is implied by the overall statement that "Programs are encouraged to adopt innovative procedures or approaches that meet the criteria and improve the program." [4]

A first step to formalize a continuous improvement program involved the appointment of a continuous improvement implementation team within the Manufacturing Engineering Technologies faculty. This team is attempting to steer the faculty and administration in the continuous improvement efforts of their existing processes, many of which have been informally improved throughout the years. Following is a description of some of the existing processes related to the TAC/ABET criteria.

The Process of Program Assessment (TC-2K -- Criterion 6) As part of a university-wide effort during the fall semester 1995, The Manufacturing Engineering Technologies \& Supervision department developed an Assessment Committee to develop an assessment tool to be sent to employers and alumni for each program in the department. With the help of the faculty and the Industrial Advisory Board, the committee developed a set of goals and objectives for each program within the department.

By the end of spring semester 1996, each program had a set of goals as well as outcome measures for those goals and objectives. Depending on the major, each program had a set of unique objectives, but at the same time, all programs share a set of common objectives that could easily be measured through surveys done by the University. It is interesting to mention that the general goals of the programs are in line with the eleven expected outcomes mentioned in Criterion number one of the new TC-2K. 
For the purposes of TAC/ABET accreditation, one of the most effective continuous improvement plan presentations for the visiting team is the five column format with five column headings as follows:

1) Expanded Institutional Goal

2) Program Intended Outcomes/Objectives

3) Assessment Criteria and Procedures

4) Assessment Results

5) Use of Results.

There should be one, or at most two, institutional goals in the first column. Outcomes and objectives in the second column are numbered with numbers carrying across the other three columns. The last column "Use of Results" shows actions or improvements made based on the assessment results. Measures to be taken if assessment results should falter or drop below expectations should also be included in the last column.

During the 1996-97 academic year, two primary data sources were developed for departmental assessment. The Department surveyed 193 employers of graduates from August 1993 through December 1995. Of these, eighty-three responded for the four programs. A second data source was a Survey of Alumni 4, 7, and 10 years out, completed by the Department of Evaluation \& Planning Services in June of 1996. One hundred ninety five surveys were sent and seventy-four $(38 \%)$ responded.

Although faculty from the four related programs in the department review the data on a program by program basis, the results are summarized for the department as a whole. This was done because of similarities in most of the goal statements, the low number of survey responses for the smaller programs, and because in many instances common courses are used to satisfy graduation requirements.

For each goal, there is an outcome measure. For each outcome measure, the survey results of the two data sources were summarized. The summary was used to modify mostly the outcome measures as well as some goals and objectives.

Follow-up activities since the first assessment data became available to the department resulted in changes to the goals and objectives as follows:

- Reviewed program goal statements by the faculty in February 1997 and by the advisory committee in April 1997, at a departmental retreat in April 1997 when changes were made to some goals and objectives. An annual assessment report was submitted to the Dean of the School of Technology in June of 1998.

- New data on some outcome measures became available during the spring semester of 1998. Faculty, at a departmental retreat, met on August 1998 and went through a major revision of goals and objectives in that meeting. In most areas, the outcome measures surpassed the departmental goals and objectives. In an area where the expectations were not met, changes in the program were initiated and no cost weekend review classes were introduced for the three hour SME certification exam which is nationally normed. SME provides extensive analysis on test outcomes of our students versus knowledge areas. 
- The new goals and objectives were discussed at the advisory meeting held in December 1998. The new data available in spring, 1999 were discussed and the necessary changes to the goals and objectives made before fall of 1999.

The University, in September of 1998, established the Academic Assessment Advisory Committee (AAAC) which is charged to review the assessment programs of all units in Academic Affairs. Annually, by June 1 of each year beginning in 1999, the AAAC provides the Vice Chancellor for Academic Affairs with a report on the overall assessment efforts in Academic Affairs, including any recommendations pertinent to the improvement of efforts.

\section{Processes Related to Other TC-2K Criteria}

Criterion 1 Students and Graduates Some faculty in the department have started doing a "continuous improvement" feedback session with their students when convenient pedagogically. Students are asked for open ended suggestions on what they think would improve their learning, increase their interest, help them at work, help them in other classes or otherwise make the class a more positive educational experience. Students are also asked for feedback on course content. In order to develop a commitment to quality, timeliness and continuous improvement in students, it is valuable to have faculty model the behavior and involve students in the culture of continuous improvement. One professor in our Purdue University Calumet School of Technology asks for written feedback once per week with positive results reported. This effort is to assess and continuously improve individual classes. Our department has a web based form to record course improvements and another to record other continuous quality improvements. Improvements and results are posted on the web.

Criterion 2 Program Characteristics EC 2000 has produced a focus on continuous improvement of curriculum in the engineering community. Jakubowski presents a continuous improvement model for curriculum development [5] which applies equally well to engineering technology programs as to engineering programs. The METS department expects to use this model along with measurable objectives defined during retreat workshops scheduled for the end of the Spring, 2000 semester. Purdue West Lafayette's MET program, with similar courses, started a learning objectives project [3] during Fall of 1996.

Criterion 3 Faculty The Purdue University Calumet METS department has started to require faculty to submit annual reports in the form of a personal continuous improvement report. Previously, annual reports were listings of yearly activities organized under the headings of teaching, scholarly activity and service. Now, each faculty member must have a mission statement or vision with goals and objectives supporting it. Each goal or objective has associated tactics or strategies that can be undertaken to implement it. The list of activities or accomplishments generated over the year is then organized so each supports a strategy or tactic. Yearly merit raises are based on an evaluation of the report.

Criterion 4 Facilities and Criterion 5 Institutional and External Support Purdue University Calumet's departments providing administrative services formed an $\mathrm{E}^{2}=\mathrm{Q}$ Quality effort (Exceeding Expectations is Quality) in 1997 [6]. Administrative services includes essentially every staff member not in an academic department including registrar, admissions, placement, 
housekeeping, police, computer services, facilities, maintenance, and so on. Approximately 30 administrators in Administrative Services were trained to become self-assessors using the Baldrige Criteria. Shortly thereafter, Administrative Services adopted the Baldrige Criteria as their self-assessment method. During the summer of 1997, a self-assessment committee and two self-assessment teams were formed to conduct the self-assessment of Administrative Services. The self-assessment teams conducted interviews with employees of Administrative Services. Interviews were also conducted with customers from all levels of the University. The result of these interviews was a self-assessment report which identified areas of Administrative Services strengths and improvement needs. The improvement needs were prioritized and six categories of improvement needs emerged as the most critical at this point in time. Six teams were formed to address each of the six categories of improvement needs. These teams built and planned the framework and infrastructure to implement the Baldrige criteria into daily operations. The six teams are:

Core Leadership

Skills Building

Baseline Assessment

Strategic Planning

Communication

Rewards and Recognition

The teams have developed a two tier time frame for the initiative. The first, building the framework and methodology to institutionalize quality into the way business was conducted in Administrative Services is completed. The larger, longer term goal is the implementation of the strategies that are being developed. This is expected to take up to 5-7 years to reach full implementation and embed quality into the culture in Administrative Services.

Criterion 7 Individual Program Criteria Although individual program criteria have not as yet been developed by the professional associations represented on TAC, our department and university are attempting to help develop the criteria in at least two program areas, Mechanical Engineering Technology (MET) and Design Drafting Technology.

Purdue University Excellence 21 Program Excellence 21 [7] is a system-wide effort by Purdue started in 1995 to explore the principles of continuous improvement and total-quality management. Developed with assistance from Motorola, Inc., Excellence 21 is designed to allow Purdue to utilize some of the tools of the business world without altering the core values or missions of the university.

Purdue's budget request for the 2001 Indiana General Assembly session will have a TQM component and will resemble a grant proposal.

\section{Conclusions}

As can be seen by the current activities outlined above, there are already many important improvement initiatives put in place by the departments and staff at Purdue University Calumet, including specifically the Manufacturing Engineering Technologies Department. However, just coming off a TAC/ABET visit of our programs which took place in September of 1999, it has become evident to us that these initiatives must become part of a formalized continuous 
improvement program. From the authors' experiences it is apparent that most Engineering Technology departments are not adequately familiar with the concept of a formal continuous improvement program, as was the case at Purdue University Calumet, and need to educate themselves in order to be able to formalize their efforts.

Bibliography

1. Danny G. Langdon, “A New Language of Work,” Quality Digest (October 1994):44-48.

2. Besterfield, Dale H., et al., Total Quality Management, $2^{\text {nd }}$ Ed. Upper Saddle River, NJ: Prentice Hall, (1999).

3. Corum, Christine L., and Pagano, Mark A., "Continuous Improvement in an MET Program," ASEE Annual Conference and Exposition Proceedings, Milwaukee, Wisconsin, (June 15-18, 1997).

4. Proposed Criteria for Accrediting Engineering Technology Programs beginning in 2001 (TC-2K), TAC of ABET, Baltimore, MD, (1999) http://www.abet.org/.

5. Jakubowski, G.S. and Calder W.T., "ABET Engineering Criteria 2000: Continuous Improvement in Engineering Education," ASME Paper 98-WA/DE-15, (November 15-20, 1998).

6. Purdue University Calumet $\mathrm{E}^{2}=\mathrm{Q}$ Quality Program, http://www.calumet.purdue.edu/public/E2=Q/

7. Depew, D.R., Purdue's "Excellence 21" Journey: Evolution, Not Revolution, Quality in Higher Education, (October, 1997), http://thorplus.lib.purdue.edu/ex21/resources/qhe/Oct97.html.

\section{GREGORY NEFF}

Gregory Neff is an Associate Professor of Mechanical Engineering Technology. He has graduate degrees in mechanical engineering, physics, and mathematics. He is a Registered Professional Engineer, a Certified Manufacturing Engineer, a Certified Manufacturing Technologist, and a Certified Senior Industrial Technologist. He has served as a TAC/ABET program accreditation visitor for the past four years. Greg is national secretary for the METDHC of the American Society of Mechanical Engineers and is METDHC chair for Region VI.

\section{SUSAN SCACHITTI}

Susan Scachitti is an Assistant Professor of Industrial Engineering Technology. She holds degrees in Industrial Engineering Technology from the University of Dayton and a Master of Business Administration in Management from North Central College. She has ten years of industrial experience. Her accomplishments include playing key roles in ISO9001 certification and establishing a benchmark for a self-directed workforce. She teaches total quality management and consults in the area of continuous improvement.

\section{MOHAMMAD A. ZAHRAEE}

Mohammad A. Zahraee is a Professor and Head of the Department of Manufacturing Engineering Technologies and Supervision. He received his Ph.D. in Theoretical and Applied Mechanics from the University of Illinois and is a registered P.E. in Indiana. He has served as the National Chair of the MET Dept. Heads Committee of ASME and is a member of the ASME Council on Education and former member of the Board on Engineering Education. He has been a TAC (Technology Accreditation Commission) evaluator for ABET since 1992. A member of the Committee on Technology Accreditation of ASME, he was elected TAC alternate for ABET in 1997, a member of TAC in 1998. He is a TAC accreditation team chair and the senior ASME TAC representative. He is chair of the ASME committee preparing MET and Design Drafting Technology program criteria for TC-2K. 